\title{
Pengendalian Lengan Robot untuk Proses Pemindahan Barang
}

\author{
William $^{1}$, Budi Kartadinata ${ }^{1}$, Linda Wijayanti ${ }^{1}$
}

\begin{abstract}
Nowadays, industry technology are developed to make productivity more efficient. The main problem that hampers the production process is using human labor. Therefore, industrial robots are developed to work more efficiently such as robots moving goods. The purpose of this research is to apply the robot arm to the process of moving goods that can be monitored and controlled remotely using Human Machine Interface (HMI). Robots require controllers as regulator of production processes such as Arduino Uno microcontroller and Programmable Logic Controller (PLC). Arduino Uno is used as a data processor from color sensor, then Arduino Uno will control the relay module which is used to communication medium with PLC. TCS230 is a color sensor that is also able to read the existence of an object. This color sensor produces digital frequencies as an output with the period that will be calculating by Arduino Uno. The object with color that have been detected will be move by the robot arm to a predetermined position. The arm of the robot moves using pneumatik and dc motors, as well as the limit switch as the x-axis position sensor of the robotic arm. The carrying of an object will be done with the air suction through a small hole that assisted by rubber lip. The pneumatik that used to suck an object has a cylindrical iron rod.
\end{abstract}

KEYWORDS: color sensor, arduino microcontroller, PLC, HMI.

\begin{abstract}
ABSTRAK: Sekarang ini, teknologi bidang industri terus dikembangkan agar produktifitas menjadi semakin lebih efisien. Permasalahan utama yang menghambat proses produksi adalah penggunaan tenaga kerja manusia. Oleh karena itu, dikembangkanlah robot industri yang mampu bekerja lebih efisien seperti robot pemindah barang. Tujuan penelitian ini adalah mengaplikasikan lengan robot untuk proses pemindahan barang yang dapat dipantau dan dikendalikan dari jarak jauh menggunakan Human Machine Interface (HMI). Robot membutuhkan kontroler sebagai pengatur proses produksi seperti mikrokontroler Arduino Uno dan Programmable Logic Controller (PLC). Arduino Uno digunakan sebagai pengolah data dari sensor warna, kemudian Arduino Uno akan mengaktifkan relay modul yang berguna sebagai media komunikasi dengan PLC. TCS230 merupakan sensor warna yang sekaligus mampu membaca keberadaan objek. Sensor warna ini menghasilkan keluaran berupa frekuensi digital yang akan dihitung periodenya oleh Arduino Uno. Benda yang telah dideteksi warnanya akan dipindahkan oleh lengan robot ke posisi yang telah ditentukan. Lengan robot bergerak menggunakan pneumatik dan motor dc, serta limit switch sebagai sensor posisi sumbu x dari lengan robot. Pengambilan benda dilakukan dengan hisapan udara melalui lubang kecil yang dibantu oleh bibir karet sebagai perekat. Pneumatik yang digunakan sebagai penghisap benda memiliki batang besi berupa silinder.
\end{abstract}

KATA KUNCI: sensor warna, mikrokontroler arduino, PLC, HMI.

\section{PENDAHULUAN}

$\mathrm{P}$ ada zaman ini, setiap industri mengupayakan agar produktifitas dapat berjalan lebih efisien. Efisiensi produksi terkendala bila proses produksi masih dikerjakan oleh tenaga kerja manusia karena manusia memiliki kelemahan dan kelelahan dalam menjalankan tugasnya. Mengatasi hal ini perusahaan besar sudah beralih ke penggunaan robot industri untuk menyelesaikan proses produksi terutama pada proses yang berbahaya atau proses yang melakukan gerakan yang sama secara terus-menerus. Contohnya adalah proses pemindahan dan pengelompokkan benda yang dilakukan secara terus-menerus dapat digantikan dengan lengan robot.

Pengetahuan mengenai pengoperasian dan gerakan yang dapat dilakukan lengan robot dalam melakukan suatu pekerjaan memerlukan pemahaman yang baik. Oleh karena itu pada penelitian ini dibuat sistem otomasi pemindahan dan pengelompokkan benda berdasarkan warna benda menggunakan lengan robot melalui kendali Programmable Logic Controller yang dilengkapi dengan Human Machine Interface (HMI) atau Supervisory Control And Data Acquisition (SCADA).

\section{LENGAN ROBOT}

Lengan robot didesain meniru lengan manusia secara umum seperti adanya sendi dan efektor ujung (jepit, hisap, atau magnet) untuk mengangkat benda [1]. Robot memerlukan sensor untuk menentukan posisi lengan, dan kontroler yang menyimpan program untuk mengatur proses gerakkan lengan robot, serta aktuator sebagai penggeraknya.

\section{PNEUMATIK}

Pneumatik berupa tabung baja yang didalamnya terdapat plat bulat dengan karet yang memisahkan isi tabung menjadi 2 bagian seperti pada Gambar 1. Tekanan udara yang dimasukkan kedalam tabung akan mendorong plat bulat sehingga batang besi yang terhubung dengan plat akan ikut bergerak maju/mundur

\footnotetext{
${ }^{1}$ Program Studi Teknik Elektro, Universitas Katolik Atma Jaya Jakarta
} 




- Gambar 1. Pneumatik

\section{SOLENOID VALVE}

Solenoid valve pneumatik adalah katup yang dikontrol menggunakan energi listrik melalui solenoida. Solenoid berfungsi untuk menggerakan piston yang dapat digerakan oleh arus AC maupun DC [2].

Terdapat berbagai macam jenis pneumatik valve tergantung jumlah lubangnya. Pneumatik valve yang biasa digunakan memiliki 2 lubang keluaran seperti Gambar 2

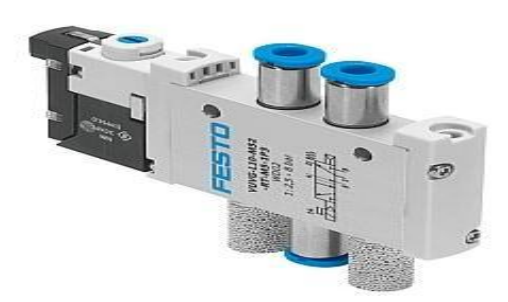

- Gambar 2. Solenoid valve Festo

\section{MOTOR ARUS SEARAH}

Motor adalah alat untuk mengubah energi listrik menjadi energi mekanik. Motor listrik terdiri dari 2 bagian yaitu rotor dan stator. Rotor merupakan bagian yang bergerak dan stator bagian yang tidak bergerak [3]. Motor arus searah seperti pada Gambar 3 merupakan salah satu motor DC yang menggunakan magnet tetap sebagai statornya. Arus listrik pada kumparan rotor berada dalam medan magnet yang dihasilkan stator sehingga menimbulkan gaya Lorentz pada rotor seperti Persamaan (1) [3]

$$
\mathrm{F}=\mathrm{B} \times \mathrm{I} \times \mathrm{L} \times \sin \alpha
$$

Keterangan:

$\mathrm{F}=$ Gaya Lorentz (newton)

$\mathrm{B}=$ Kuat medan magnet (tesla) $\mathrm{I}=$ Arus listrik (ampere)

$\mathrm{L}=$ Panjang kawat (meter)

$\alpha=$ sudut yang dibentuk B dan I

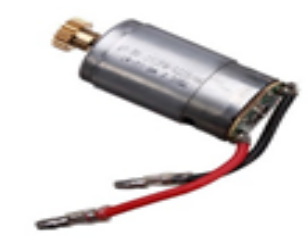

Gambar 3. Motor arus searah

\section{PROGRAMMABLE LOGIC CONTROLLER}

Programmable Logic Controller (PLC) merupakan sistem pengendali yang didesain untuk industri. PLC menggunakan memori yang dapat diprogram untuk menyimpan secara internal instruksi-instruksi dengan fungsi- fungsi spesifik seperti logika, urutan, pewaktuan, pencacahan, dan operasi aritmatik untuk mengendalikan mesin atau proses melalui modul I/O digital maupun analog deprogram [4]. Bahasa pemrograman yang digunakan dapat berupa ladder diagram, function block atau statement list. 


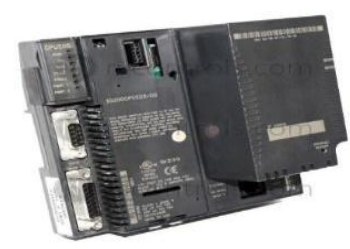

- Gambar 5. PLC Versamax GE Fanuc

\section{ARDUINO UNO}

Arduino Uno adalah salah satu kit mikrokontroler yang berbasis pada ATmega28 [5]. Arduino Uno memiliki14 pin digital input/output, 6 analog input, sebuah resonator keramik 16MHz, koneksi USB, pin power input, ICSP header, dan sebuah tombol reset dibentuk menjadi seperti pada Gambar 6

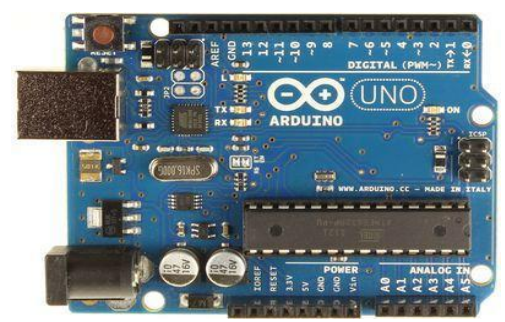

- Gambar 6. Arduino Uno

\section{SENSOR WARNA}

Sensor warna, TCS230, merupakan serangkaian photodiode yang disusun secara matriks $8 \times 8$ dengan 16 buah photodiode yang berfungsi sebagai filter masing-masing warna dan filter tanpa warna [6]. Kontruksi sensor warna TCS230 dapat dilihat pada Gambar 7 [6].


- Gambar 7. Konstruksi sensor warna TCS230

Sensor warna,TCS230, memiliki selektor $\mathrm{S}_{2}$ dan $\mathrm{S}_{3}$ yang berfungsi untuk memilih kelompok konfigurasi photodiode yang akan digunakan. Konfigurasi selektor $\mathrm{S}_{2}$ dan $\mathrm{S}_{3}$ dalam pemilihan kelompok photodiode ditetapkan pada Tabel 1.

Tabel 1. Konfigurasi $S_{2}$ dan $S_{3}$ Sensor warna TCS230 [6]

\begin{tabular}{|l|l|c|}
\hline $\mathbf{S}_{\mathbf{2}}$ & $\mathbf{S}_{\mathbf{3}}$ & Photodiode yang aktif \\
\hline 0 & 0 & Pemfilter Merah \\
\hline 0 & 1 & Pemfilter Biru \\
\hline 1 & 0 & Tanpa Filter \\
\hline 1 & 1 & Pemfilter Hijau \\
\hline
\end{tabular}

Photodiode akan mengeluarkan arus yang besarnya sebanding dengan kadar warna cahaya yang diterimanya. Frekuensi output dapat diskalakan dengan mengatur selektor $\mathrm{S}_{0}$ dan $\mathrm{S}_{1}$. Skala output ditetapkan pada Tabel 2. Komposisi warna RGB (red, green, blue) dihitung berdasarkan frekuensinya.

- Tabel 2. Skala output $\mathrm{S}_{0}$ dan $\mathrm{S}_{1}$ sensor warna TCS230 [6]

\begin{tabular}{|c|c|c|}
\hline $\mathbf{S}_{\mathbf{0}}$ & $\mathbf{S}_{\mathbf{1}}$ & Skala Frekuensi output \\
\hline 0 & 0 & Power Down \\
\hline 0 & 1 & $2 \%$ \\
\hline 1 & 0 & $20 \%$ \\
\hline 1 & 1 & $100 \%$ \\
\hline
\end{tabular}




\section{HUMAN MACHINE INTERFACE}

Human Machine Interface (HMI) menampilkan proses kerja mesin yang sedang berlangsung di lapangan secara animasi pada layar monitor, sehingga dengan HMI operator lebih mudah dalam melakukan pekerjaan fisik [7]. HMI dapat terhubung dengan logika input, output, memory, serta register pada PLC. Logika yang sudah masuk kedalam database HMI dapat diambil dan diubah sesuai kebutuhan, sehingga pergerakkan mesin dapat dimonitor dan masukan dapat dikontrol dengan HMI.

\section{KONSEP PERANCANGAN}

Robot industri bekerja dengan proses awal memasukkan benda yang akan dikelompokkan berdasarkan warnanya (merah, biru, dan hijau) ke posisi awal benda. Ketika tombol (push button) start ditekan operator, lengan robot akan terangkat dan motor akan memutar lengan sampai posisi lengan siap mengambil benda. Pneumatik pertama akan mendorong benda ke bagian sensor warna dan keberadaan benda akan terbaca, serta dideteksi warnanya. Setelah terbaca sensor, pneumatik kedua akan mendorong benda ke bagian pengambilan benda. Lengan robot akan turun dan akan menghisap benda, serta memindahkannya ke bagian yang sesuai warnanya seperti pada Gambar 8. Masing-masing warna akan dipindahkan sebanyak 3 kali. Jika ada benda ke-4 dengan warna yang sama, lengan robot akan memindahkannya ke bagian reject. Ketika seluruh warna sudah masing-masing 3 dipindahkan, proses kerja sistem selesai.

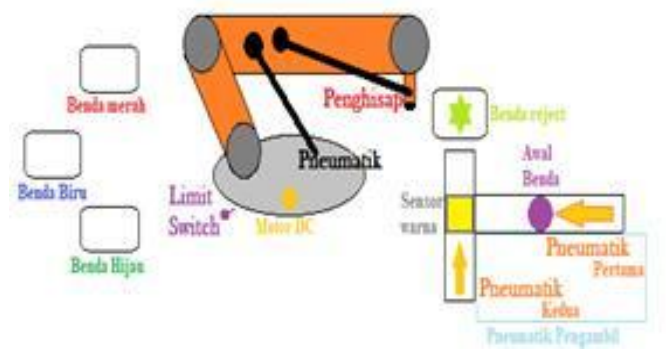

- Gambar 8. Struktur Sistem

\section{PERANCANGAN PERANGKAT KERAS}

Perancangan perangkat keras dibagi menjadi 2 bagian yaitu perancangan mikrokontroler arduino uno dan perancangan PLC yang masing-masing memiliki masukan dan keluaran. Masukan dari arduino adalah sensor warna, dan keluarannya adalah relay modul. Sensor warna yang digunakan dapat mendeteksi ada tidaknya benda dengan memanfaatkan warna clear. Diagram blok perangkat keras digambarkan seperti Gambar 9.

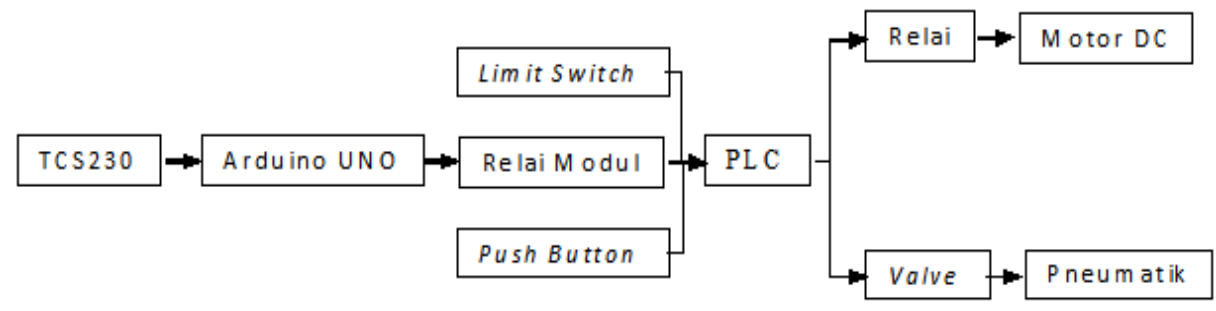

- Gambar 9. Diagram blok perangkat keras

Perancangan sistem dijelaskan sebagai berikut:

1. TCS230 merupakan sensor warna yang berfungsi sebagai pendeteksi warna benda yang ada didepannya.Keluaran sensor warna berupa sinyal frekuensi yang dikirimkan ke salah satu pin Arduino Uno untuk diolah datanya sehingga dapat menetapkan warna benda merah, biru, atau hijau.

2. Relay modul berfungsi sebagai media komunikasi/perantara antara arduino dan PLC karena tegangan keluaran pin arduino sebesar 5 volt, sedangkan masukan pin PLC membutuhkan tegangan sebesar 24 volt. Push button digunakan sebagai tombol start, reset, dan stop.

3. Push button dihubungkan dengan Vcc dan pin input PLC.

4. Limit switch digunakan sebagai sensor posisi. Terdapat 5 posisi yang telah ditetapkan yaitu posisi pengambilan benda, benda reject, benda merah, benda biru, dan benda hijau. Pada sisi dinding alas lengan 
dipasangkan suatu bantalan sebagai penekan limit switch. Limit switch dihubungkan dengan tegangan positif suplai $24 \mathrm{~V}$ dan pin input PLC.

5. Relay digunakan sebagai pengatur arah arus motor DC seperti driver, digunakan 2 buah relay yang saling terhubung dengan motor DC. Kumparan relay dihubungkan dengan ground tegangan suplai dan pin output PLC.

6. Motor DC digunakan sebagai penggerak sumbu $\mathrm{X}$ dari sistem. Alas lengan robot terdiri 3 lapis: lapisan paling bawah adalah gear tetap yang besar, dilanjutkan dengan besi bundar, lalu diatasnya berupa kayu tebal yang menutupi $3 / 4$ besi bundar. Besi bundar diberi sebuah lubang yang berguna untuk motor. Motor DC dengan ujung mata gear dimasukkan kedalam lubang, sehingga ujung mata gear motor akan terhubung dengan gear alas.

7. Valve berfungsi sebagai pengontrol aliran udara dari kompressor. Valve pertama dihubungkan dengan pembalik aliran udara sehingga keluarannya akan menghisap. Valve kedua berfungsi untuk mengubah 2 kondisi lengan robot yaitu naik dan turun. Valve ketiga berfungsi untuk menggerakkan 2 pneumatik pengambil benda diawal. Solenoid valve dihubungkan ke ground tegangan suplai dan pin output PLC.

\section{RANGKAIAN MIKROKONTROLER ARDUINO UNO}

Rangkaian mikrokontroler Arduino Uno berfungsi untuk membaca frekuensi dan mengolah data yang berasal dari snsor warna, serta mengendalikan relay modul. Rangkaian skematik dari mikrokontroler Arduino Uno diperlihatkan pada Gambar 10 dengan konfigurasi pin sebagai berikut:

1. Pin Vin dihubungkan ke tegangan positif $(+\mathrm{V})$ suplai DC 5v.

2. Pin Gnd 1 dihubungkan ke tegangan negatif (-V) suplai DC 5v.

3. Pin Gnd 2 dihubungkan ke ground pada TCS230.

4. Pin 5v dihubungkan ke Vcc pada TCS230.

5. Pin 4, 5, 6, dan 7 dihubungkan ke pin S0, S1, S2, dan S3 pada TCS230, bertipe OUTPUT.

6. Pin 8 dihubungkan ke pin out pada TCS230, bertipe INPUT.

7. Pin 10, 11, 12, dan 13 dihubungkan ke IN1, IN2, IN3, dan IN4 pada relay modul, bertipe OUTPUT.

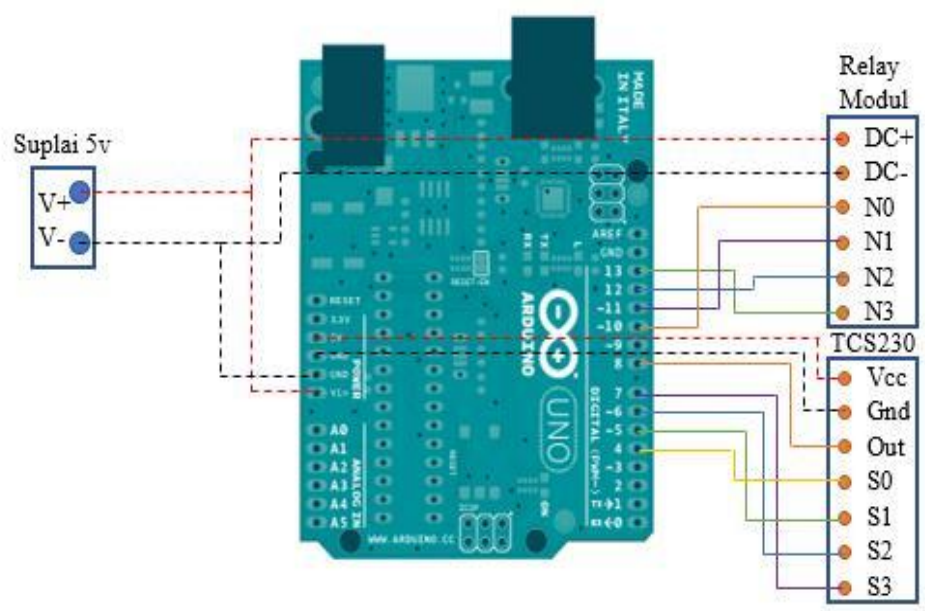

Gambar 10. Skematik mikrokontroler Arduino Uno

\section{RANGKAIAN REALY MODUL}

Rangkaian relay modul berfungsi sebagai media komunikasi/perantara antara mikrokontroler Arduino Uno dengan PLC. Relay modul memiliki masukan DC+ dan DC- yang berfungsi sebagai sumber tenaga untuk mengaktifkan kumparan relay. Masukan IN1, IN2, IN3, dan IN4 berfungsi sebagai kontrol untuk mengaktifkan relay bila diberikan tegangan positif 5V. Pin NC, COM, dan NO merupakan pin yang tersedia untuk tiap relay. Rangkaian skematik relay modul diperlihatkan pada Gambar 11. 


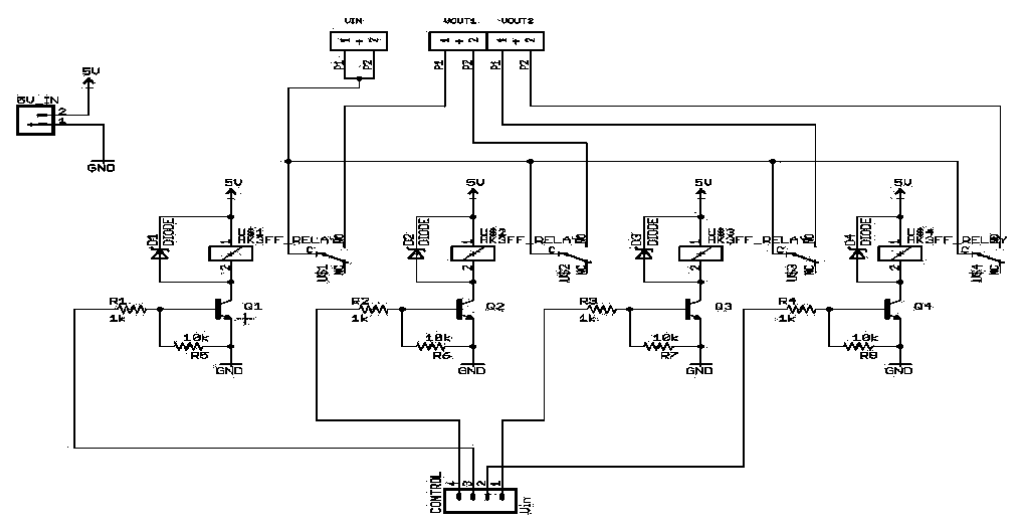

- Gambar 11. Skematik relay modul

\section{RANGKAIAN PROGRAMMABLE LOGIC CONTROLLER}

Rangkaian PLC berfungsi sebagai kontroler utama dari sistem. Rangkaian inputloutput modul PLC diperlihatkan pada Gambar 12 dengan konfigurasi pin sebagai berikut:

1. Pin input 1, 2, dan 3 dihubungkan ke push button dengan pin push button lainnya dihubungkan ke tegangan positif suplai $24 \mathrm{~V}$.

2. Pin input 4, 5, 6, dan 12 dihubungkan ke pin NO 1 sampai 4 pada relay modul yang COM-nya dihubungkan ke tegangan positif suplai $24 \mathrm{~V}$.

3. Pin input 7, 8, 9, 10, dan 11 dihubungkan ke NO dari limit switch sensor posisi yang COM-nya dihubungkan ke tegangan positif suplai $24 \mathrm{~V}$.

4. Pin input 17 dan 18 dihubungkan ke ground suplai $24 \mathrm{~V}$.

5. Pin output $1,3,5,7,9,11,13$, dan 15 (angka ganjil) dihubungkan dengan tegangan positif suplai $24 \mathrm{~V}$.

6. Pin output 2, 4, 6, 8, dan 10 dihubungkan ke port kabel pada solenoid valve.

7. Pin output 12 dan 14 dihubungkan ke salah satu pin kumparan pada relay, dan pin kumparan lainnya dihubungkan ke ground suplai $24 \mathrm{~V}$.



- Gambar 12. Rangkaian input/output modul PLC

\section{RANGKAIAN ALIRAN UDARA PNEUMATIK}

Rangkaian aliran udara pneumatik berfungsi sebagai pengontrol gerakkan pneumatik oleh valve. Valve dapat mengubah aliran udara dengan mengaktifkan solenoid yang membutuhkan tegangan 24V. Rangkaian aliran udara pneumatik diperlihatkan pada Gambar 13.



Gambar 13. Rangkaian aliran udara pneumatik 


\section{RANGKAIAN MOTOR DRIVER DENGAN RELAY}

Rangkaian motor driver berfungsi sebagai pengaman dan pengatur arah gerak untuk motor dc. Motor driver dirangkai menggunakan 2 buah relay yang memiliki kumparan dengan tegangan aktif $24 \mathrm{~V}$, karena relay akan diaktifkan/dikontrol menggunakan PLC. Rangkaian motor driver menggunakan 2 buah relay diperlihatkan seperti pada Gambar 14.



- Gambar 14. Rangkaian motor driver dengan 2 buah relay

\section{PERANCANGAN PERANGKAT LUNAK}

Perancangan perangkat lunak menggunakan 3 buah program berbeda yaitu untuk mikrokontroler Arduino Uno, PLC (Proficy), dan HMI (iFIX). Secara singkat, program PLC diperlihatkan dalam bentuk diagram alir pada Gambar 15.

Program mikrokontroler Arduino Uno berawal dengan mengatur output frekuensi scaling yang berfungsi sebagai pengatur keluaran dari sensor warna. Setiap pembacaan salah satu warna, sensor perlu diberikan sinyal tertentu kemudian dibaca frekuensinya untuk setiap warna. Arduino Uno akan memberikan sinyal keluaran untuk mengaktifkan relay modul.

\section{PERANCANGAN HUMAN MACHINE INTERFACE}

Perancangan Human Machine Interface (HMI) menggunakan aplikasi iFIX. Jika aplikasi iFIX dan PLC sudah terhubung, langkah selanjutnya adalah membuat database untuk input, output, memory, dan register.

Pembuatan animasi HMI dengan aplikasi iFIX dilakukan pada workspace dan dapat memilih object sesuai keinginan. Setiap penggunaan HMI, operator harus selalu menghubungkan aplikasi iFIX dengan PLC. Operator harus membuka database dan SCU".
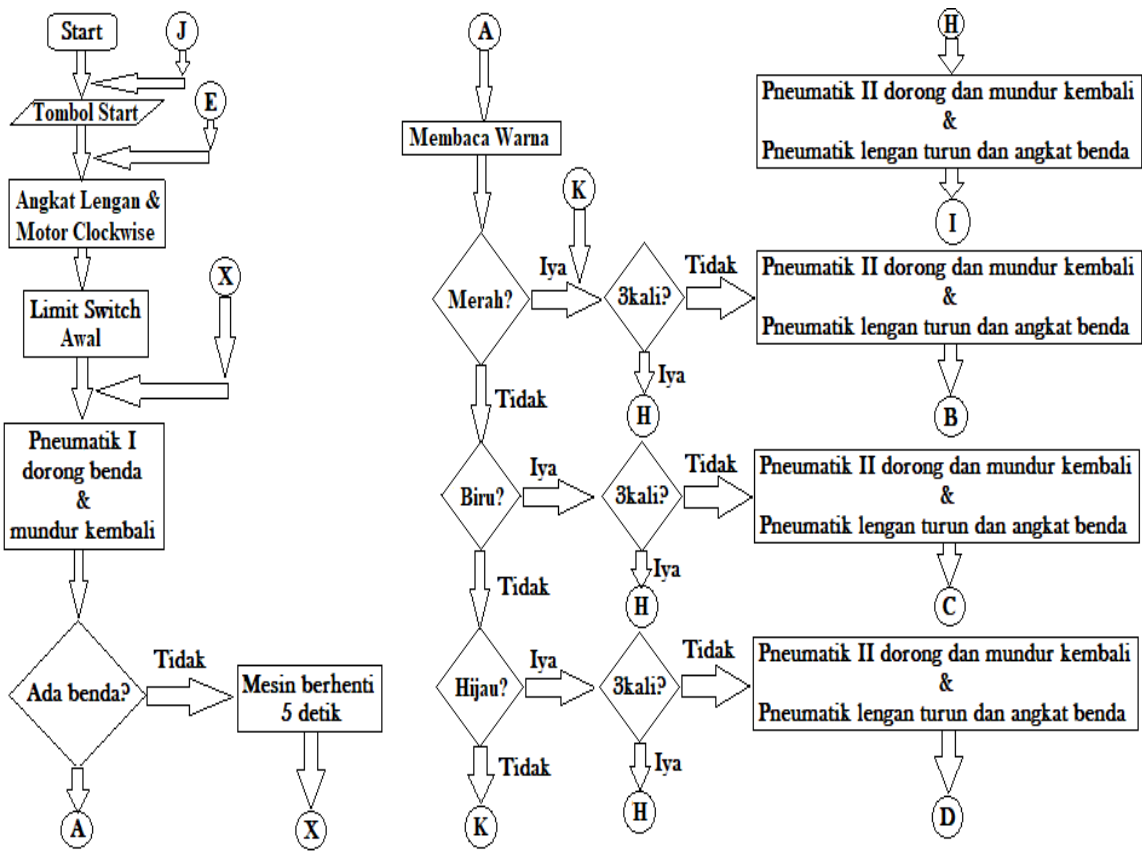


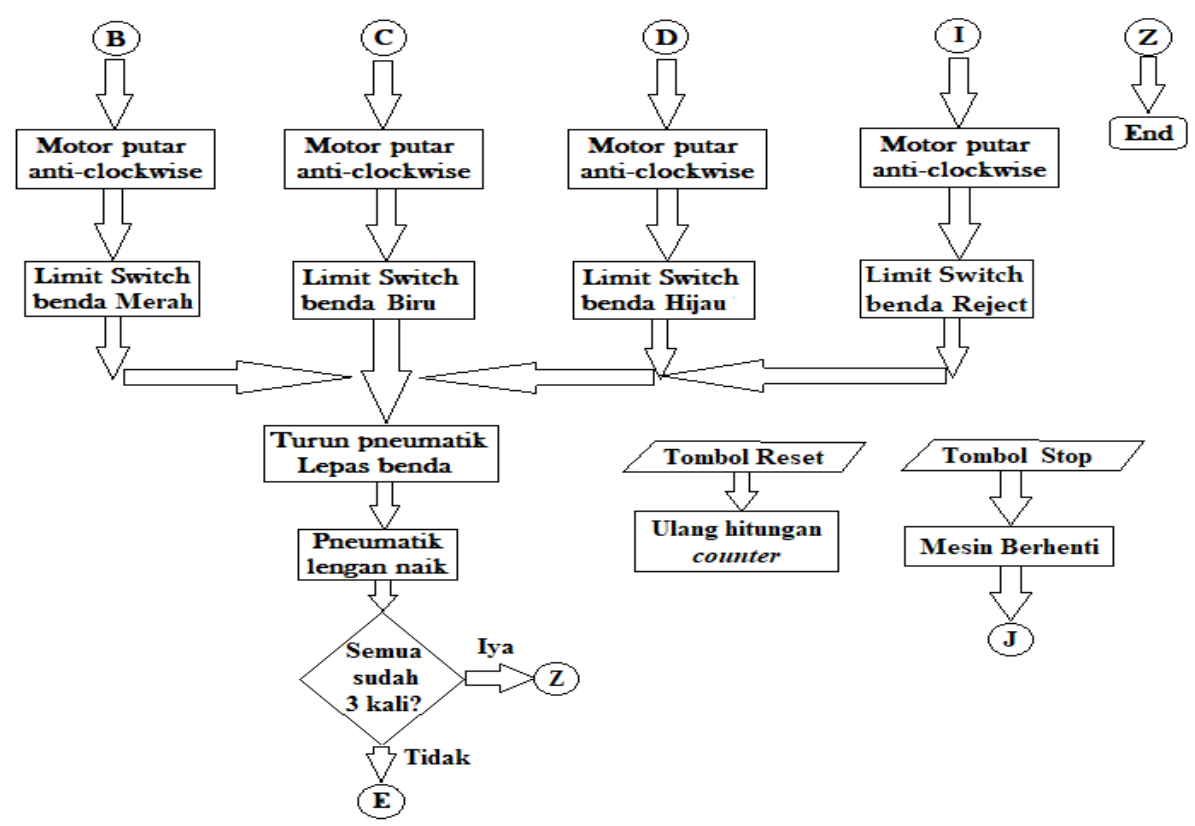

\section{PENGUJIAN SENSOR WARNA}

Pengujian sensor warna TCS230 bertujuan untuk memastikan photodiode pada sensor warna berfungsi dengan baik untuk warna merah, biru, hijau, dan clear. Hasil respon frekuensi dari sensor warna ditampilkan pada Gambar 16, Gambar 17, Gambar 18 dan Gambar 19.

00 COM3 (Arduino/Genuino Uno)
\begin{tabular}{|llll}
\hline \\
$\mathrm{R}=36$ & $\mathrm{G}=120$ & $\mathrm{~B}=91$ & $\mathrm{C}=22$ \\
$\mathrm{R}=36$ & $\mathrm{G}=120$ & $\mathrm{~B}=92$ & $\mathrm{C}=23$ \\
$\mathrm{R}=36$ & $\mathrm{G}=121$ & $\mathrm{~B}=91$ & $\mathrm{C}=23$ \\
$\mathrm{R}=36$ & $\mathrm{G}=120$ & $\mathrm{~B}=91$ & $\mathrm{C}=23$ \\
$\mathrm{R}=36$ & $\mathrm{G}=120$ & $\mathrm{~B}=91$ & $\mathrm{C}=23$ \\
$\mathrm{R}=35$ & $\mathrm{G}=120$ & $\mathrm{~B}=91$ & $\mathrm{C}=23$ \\
$\mathrm{R}=36$ & $\mathrm{G}=121$ & $\mathrm{~B}=92$ & $\mathrm{C}=23$ \\
$\mathrm{R}=36$ & $\mathrm{G}=121$ & $\mathrm{~B}=91$ & $\mathrm{C}=23$ \\
$\mathrm{R}=36$ & $\mathrm{G}=120$ & $\mathrm{~B}=91$ & $\mathrm{C}=23$ \\
$\mathrm{R}=30$ & $\mathrm{G}=114$ & $\mathrm{~B}=85$ & $\mathrm{C}=22$ \\
$\mathrm{R}=36$ & $\mathrm{G}=120$ & $\mathrm{~B}=91$ & $\mathrm{C}=23$ \\
$\mathrm{R}=36$ & $\mathrm{G}=120$ & $\mathrm{~B}=91$ & $\mathrm{C}=23$ \\
$\mathrm{R}=36$ & $\mathrm{G}=121$ & $\mathrm{~B}=92$ & $\mathrm{C}=23$ \\
$\mathrm{R}=36$ & $\mathrm{G}=120$ & $\mathrm{~B}=90$ & $\mathrm{C}=23$ \\
$\mathrm{R}=36$ & $\mathrm{G}=120$ & $\mathrm{~B}=91$ & $\mathrm{C}=23$ \\
\end{tabular}

Gambar 16. Respon frekuensi warna merah

COM3 (Arduino/Genuino Uno)

\begin{tabular}{lllll}
\hline \\
\hline$R=128$ & $\mathrm{G}=86$ & $\mathrm{~B}=99$ & $\mathrm{C}=33$ \\
$\mathrm{R}=126$ & $\mathrm{G}=85$ & $\mathrm{~B}=97$ & $\mathrm{C}=32$ \\
$\mathrm{R}=126$ & $\mathrm{G}=85$ & $\mathrm{~B}=96$ & $\mathrm{C}=32$ \\
$\mathrm{R}=124$ & $\mathrm{G}=84$ & $\mathrm{~B}=96$ & $\mathrm{C}=32$ \\
$\mathrm{R}=125$ & $\mathrm{G}=84$ & $\mathrm{~B}=97$ & $\mathrm{C}=32$ \\
$\mathrm{R}=125$ & $\mathrm{G}=85$ & $\mathrm{~B}=90$ & $\mathrm{C}=32$ \\
$\mathrm{R}=124$ & $\mathrm{G}=84$ & $\mathrm{~B}=96$ & $\mathrm{C}=32$ \\
$\mathrm{R}=124$ & $\mathrm{G}=84$ & $\mathrm{~B}=96$ & $\mathrm{C}=26$ \\
$\mathrm{R}=125$ & $\mathrm{G}=84$ & $\mathrm{~B}=97$ & $\mathrm{C}=32$ \\
$\mathrm{R}=125$ & $\mathrm{G}=82$ & $\mathrm{~B}=97$ & $\mathrm{C}=32$ \\
$\mathrm{R}=124$ & $\mathrm{G}=84$ & $\mathrm{~B}=96$ & $\mathrm{C}=32$ \\
$\mathrm{R}=119$ & $\mathrm{G}=85$ & $\mathrm{~B}=96$ & $\mathrm{C}=32$ \\
$\mathrm{R}=125$ & $\mathrm{G}=84$ & $\mathrm{~B}=96$ & $\mathrm{C}=32$ \\
$\mathrm{R}=123$ & $\mathrm{G}=84$ & $\mathrm{~B}=96$ & $\mathrm{C}=32$ \\
$\mathrm{R}=125$ & $\mathrm{G}=84$ & $\mathrm{~B}=97$ & $\mathrm{C}=32$ \\
$\mathrm{R}=125$ & $\mathrm{G}=85$ & $\mathrm{~B}=96$ & $\mathrm{C}=32$
\end{tabular}

- Gambar 18. ResponfFrekuensi warna hijau



- Gambar 17. Respon frekuensi warna biru

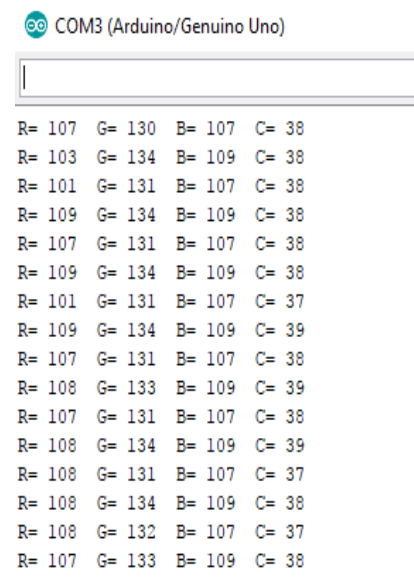

- Gambar 19. Respon frekuensi warna clear

\section{PENGUJIAN HUMAN MACHINE INTERFACE}

Pengujian human machine interface (HMI) bertujuan untuk memastikan HMI berhasil terhubung dan mampu mengontrol serta memonitor sistem secara real-time. Pengujian dilakukan dengan menghubungkan HMI 
yang telah dibuat dengan PLC, membuka database HMI, dan SCU-nya. Tombol "switch to run" ditekan, maka animasi untuk kontrol dan monitor sudah dapat diuji. Tampilan HMI diperlihatkan pada Gambar 20.



- Gambar 20. Tampilan animasi sistem alat pada HMI

\section{PENGUJIAN KESELURUHAN SISTEM}

Pengujian keseluruhan sistem bertujuan untuk memastikan setiap modul bekerja dengan baik ketika digabungkan menjadi satu sistem. Pneumatik 1 dan pneumatik 2 akan menyala secara bergantian sampai sensor warna mendeteksi keberadaan benda. Setelah sensor mendeteksi benda dan warnanya, lengan robot akan turun untuk mengambil benda dan membawa benda ke posisi yang telah ditetapkan. Pengujian saat lengan robot mengambil benda diperlihatkan pada Gambar 21, dan saat lengan robot menempatkan benda pada posisinya diperlihatkan pada Gambar 22.



- Gambar 21. Lengan robot mengambil benda

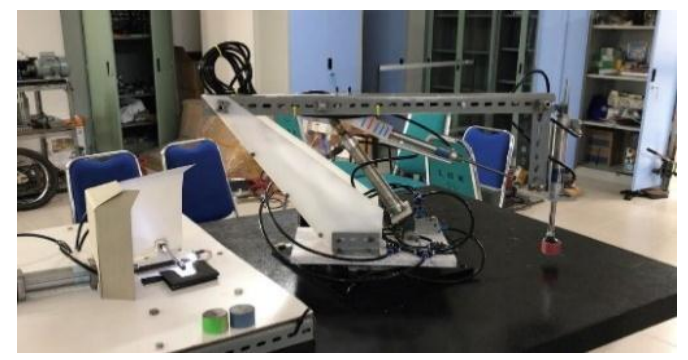

- Gambar 22. Lengan robot menempatkan benda

\section{PENGUJIAN BERAT BENDA}

Pengujian berat benda bertujuan untuk menganalisis berapa berat maksimal benda yang mampu diangkat oleh lengan. Pengujian dilakukan dengan menggunakan beberapa benda yang berbeda berat. Hasil pengujian ditampilkan pada Tabel 3.

Tabel 3. Pengujian berat benda pada sistem

\begin{tabular}{|c|c|c|}
\hline Berat benda (gram) & Pengambilan benda & Penempatan benda \\
\hline 45 & Berhasil & Berhasil \\
\hline 55 & Berhasil & Berhasil \\
\hline 65 & Berhasil & Berhasil \\
\hline 75 & Berhasil & Sesekali berhasil \\
\hline
\end{tabular}




\begin{tabular}{|l|l|l|}
\hline 85 & Berhasil & Gagal \\
\hline
\end{tabular}

\section{KESIMPULAN}

Berdasarkan perancangan sistem, realisasi sistem, dan pengujian sistem, lengan robot pemindah barang dengan bantuan human machine interface (HMI) dapat ditarik simpulan bahwa lengan robot dapat beroperasi mengambil dan menempatkan benda sesuai posisi peletakkan yang dirancang dengan berat benda maksimum 65 gram.Kerja dari sistem dapat dimonitor dan dikendalikan menggunakan HMI secara real-time.

\section{DAFTAR PUSTAKA}

[1] Syam, R. 2015. Seri Buku Ajar Robotika: Kinematika dan Dinamika Robot Lengan. Makassar: Universitas Hassanuddin.

[2] Sumbodo, W., Setiadi, R., dan Poedjiono, S. 2017. Pneumatik \& Hidrolik. Yogyakarta: Deepublish Wildi, T. 2000. Electrical Machines, Drives, and Power Systems. New Jersey: Prentice Hall.

[3] Wildi, T. 2000. Electrical Machines, Drives, and Power Systems. New Jersey: Prentice Hall

[4] Chakraborty, K., De, P., and Roy, I. 2016. Industrial Application of Programmable Logic Controllers and Scada. Hamburg: Anchor Academic Publishing.

[5] Nussey, J. 2013. Arduino for Dummies. West Sussex: John Wiley \& Sons.

[6] Elektronika Dasar. 2013. Sensor warna TCS230. http://elektronikadasar.web.id/sensor-warna-tcs230/. 9 Juli 2012.

[7] Boyer, Stuart A. 2010. SCADA : Supervisory Control and Data Acquisition. New York: International Society of Automation (ISA). 